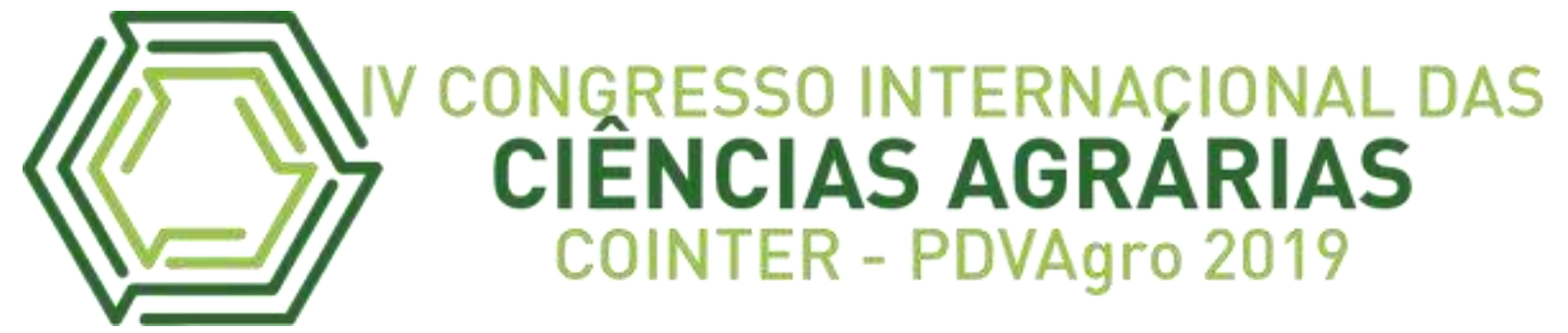

\title{
INDICADORES FÍSICOS E QUÍMICOS DE QUALIDADE DE ÁGUA E SOLO EM CULTURAS DE TOMATE E PIMENTÃO EM SÃO JOSÉ DO BELMONTE-PE
}

\section{INDICADORES FÍSICOS Y QUÍMICOS DE LA CALIDAD DEL AGUA Y EL SUELO EN TOMATE Y CULTIVOS DE ALIMENTOS EN SÃO JOSÉ DO BELMONTE-PE}

\section{PHYSICAL AND CHEMICAL INDICATORS OF WATER AND SOIL QUALITY IN TOMATO AND FOOD CROPS IN SÃO JOSÉ DO BELMONTE-PE}

\author{
Apresentação: Oral \\ Adriana Rodrigues dos Reis ${ }^{1}$; Maria Fabíola Sobreira Alves de Carvalho ${ }^{2}$; \\ Suzana Pedroza da Silva ${ }^{3}$
}

\section{DOI: https://doi.org/10.31692/2526-7701.IVCOINTERPDVAgro.2019.0006}

\begin{abstract}
Resumo
Desde o início da civilização o homem tem feito uso dos recursos hídricos com o intuito de criar alternativas para a sua sobrevivência. Uma das atividades realizadas por ele para esta finalidade é a produção agrícola, que exige o uso desses recursos em boas condições para que possa suprir o teor de nutrientes que as plantas necessitam para o seu desenvolvimento. Dentre os produtos cultivados pelo homem estão as hortaliças que são ricas em nutrientes e vitaminas essenciais para a nutrição humana. Diversas espécies de hortaliças são produzidas em várias partes do mundo, sendo comercializadas em grande escala. Porém, o aumento populacional e as mudanças tecnológicas impulsionaram o método convencional de produção que apresenta desvantagens para o meio ambiente, comprometendo os recursos hídricos e até mesmo a saúde do homem, por fazer uso de insumos químicos para a proteção das plantas contra pragas e insetos. Partindo da premissa de que as hortaliças são fontes para uma alimentação saudável, o presente trabalho teve como objetivo avaliar os indicadores de qualidade de água e solo utilizados no cultivo do tomate (Lycopersicon esculentum Mill.) e pimentão (Capsicum annuum L.). Os indicadores para análise de água foram $\mathrm{o} \mathrm{pH}$, temperatura, condutividade, alcalinidade e acidez, oxigênio dissolvido, gás carbônico, nitratos, dureza total, dureza de cálcio e magnésio e cloretos. Apenas o oxigênio dissolvido não apresentou concentrações de acordo com a resolução. Para as análises de solo foram determinados $\mathrm{pH}$, fósforo, cálcio, magnésio, potássio, sódio, alumínio, hidrogênio, ferro, cobre, zinco, manganês, matéria orgânica. A partir dos resultados foram calculadas a soma de bases, a capacidade de troca de cátion, a saturação por alumínio e a saturação por bases. Os macronutrientes cálcio, magnésio e potássio e os micronutrientes ferro, cobre, zinco e manganês apresentaram valores fora de proporção. Além desses parâmetros, foi determinada a
\end{abstract}

\footnotetext{
${ }^{1}$ Licenciada em Química, Universidade Federal Rural de Pernambuco, E-mail: drycareis89@hotmail.com

${ }^{2}$ Licenciada em Química, Universidade Federal Rural de Pernambuco, E-mail: fabiola_carvalho17@hotmail.com

${ }^{3}$ Doutora em Engenharia Química, Universidade Federal Rural de Pernambuco, E-mail: suzpedroza@gmail.com
} 
análise granulométrica (teores de areia, silte e argila) que indicou um solo areno-argiloso. Os resultados demonstraram que o solo estudado possui composição adequada para o plantio de hortaliças. No entanto, para que água utilizada na irrigação fique dentro dos padrões, são necessárias correções do sistema de manejo de cultura do local.

Palavras-Chave: Caracterização Físico-química. Hortaliças. Manejo de Água e Solo.

\title{
Resumen
}

Desde el comienzo de la civilización, el hombre ha hecho uso de los recursos hídricos para crear alternativas para su supervivencia. Una de las actividades que realiza con este propósito es la producción agrícola, que requiere el uso de estos recursos en buenas condiciones para que pueda suministrar el contenido de nutrientes que las plantas necesitan para su desarrollo. Entre los productos cultivados por el hombre se encuentran los vegetales que son ricos en nutrientes y vitaminas esenciales para la nutrición humana. Varias especies de vegetales se producen en varias partes del mundo y se comercializan a gran escala. Sin embargo, el crecimiento de la población y los cambios tecnológicos han impulsado el método de producción convencional que tiene desventajas para el medio ambiente, comprometiendo los recursos hídricos e incluso la salud humana mediante el uso de insumos químicos para proteger las plantas contra plagas e insectos. . Basado en la premisa de que los vegetales son fuentes de alimentación saludable, el presente trabajo tuvo como objetivo evaluar los indicadores de calidad del agua y el suelo utilizados en el cultivo de tomate (Lycopersicon esculentum Mill.) Y pimienta (Capsicum annuum L.). Los indicadores para el análisis del agua fueron $\mathrm{pH}$, temperatura, conductividad, alcalinidad y acidez, oxígeno disuelto, dióxido de carbono, nitratos, dureza total, dureza de calcio y magnesio y cloruros. Sólo el oxígeno disuelto no presentó concentraciones de acuerdo con la resolución. Para el análisis del suelo se determinaron $\mathrm{pH}$, fósforo, calcio, magnesio, potasio, sodio, aluminio, hidrógeno, hierro, cobre, zinc, manganeso, materia orgánica. A partir de los resultados, se calcularon la suma de bases, la capacidad de intercambio de cationes, la saturación de aluminio y la saturación de bases. Los macronutrientes calcio, magnesio y potasio y los micronutrientes hierro, cobre, zinc y manganeso presentaron valores fuera de proporción. Además de estos parámetros, el análisis granulométrico (contenido de arena, limo y arcilla) se determinó para indicar un suelo franco arenoso. Los resultados mostraron que el suelo estudiado tiene una composición adecuada para la siembra de hortalizas. Sin embargo, para que el agua utilizada en el riego esté dentro de los estándares, se requieren correcciones del sistema local de manejo de cultivos.

Palabras Clave: Caracterización física y química. Verduras Manejo de agua y suelo.

\begin{abstract}
Since the beginning of civilization man has made use of water resources in order to create alternatives for their survival. One of the activities carried out by it for this purpose is agricultural production, which requires the use of these resources in good conditions so that it can supply the nutrient content that plants need for their development. Among the products grown by man are the vegetables that are rich in nutrients and vitamins essential for human nutrition. Several species of vegetables are produced in various parts of the world and are marketed on a large scale. However, population growth and technological changes have
\end{abstract}


boosted the conventional method of production that has disadvantages to the environment, compromising water resources and even human health by making use of chemical inputs to protect plants against pests and insects . Based on the premise that vegetables are sources for healthy eating, the present work had the objective of evaluating the water and soil quality indicators used in tomato (Lycopersicon esculentum Mill.) And pepper (Capsicum annuum L.) cultivation. The indicators for water analysis were $\mathrm{pH}$, temperature, conductivity, alkalinity and acidity, dissolved oxygen, carbon dioxide, nitrates, total hardness, calcium and magnesium hardness and chlorides. Only the dissolved oxygen did not present concentrations according to the resolution. For the soil analysis were determined $\mathrm{pH}$, phosphorus, calcium, magnesium, potassium, sodium, aluminum, hydrogen, iron, copper, zinc, manganese, organic matter. From the results, the sum of bases, cation exchange capacity, aluminum saturation and base saturation were calculated. The macronutrients calcium, magnesium and potassium and the micronutrients iron, copper, zinc and manganese presented values out of proportion. In addition to these parameters, the granulometric analysis (sand, silt and clay contents) was determined to indicate a sandy loam soil. The results showed that the studied soil has adequate composition for the planting of vegetables. However, for water used in irrigation to be within the standards, corrections of the local crop management system are required.

Keywords: Physical and chemical characterization. Vegetables. Water and Soil Handling.

\section{Introdução}

O homem sempre tem se preocupado em criar alternativas que garantam a sua sobrevivência e facilitem seu desenvolvimento dentro da sociedade, uma dessas alternativas está relacionada ao uso dos recursos naturais como a água e o solo que são de fundamental importância para a produção do próprio alimento. Com o desenvolvimento da agricultura, houve a necessidade de criar técnicas e instrumentos de trabalho que facilitassem a produção agrícola, a princípio destinada apenas para o grupo familiar (CARRARO, 1997).

A partir dos anos sessenta, com o processo de modernização, novas tecnologias surgiram modificando o sistema agrícola que deixou de ser uma atividade familiar para se tornar um negócio, uma vez que, com o aumento da população passou a suprir as necessidades das cidades em expansão (CARRARO, 1997). Com isso o uso dos recursos hídricos se tornou cada vez mais necessário, desde então o homem passou a extrapolar os limites naturais do meio para benefício próprio. O desejo de produzir em grande quantidade, levou o homem a intensificar o uso do solo e investir no uso de defensivos agrícolas, revolucionando à base técnica da agricultura. No entanto, essa alternativa trouxe mudanças negativas ao meio ambiente, pois a utilização dessas práticas de forma inadequada tem causado erosão, infertilidade, perda da matéria orgânica do solo, perigo à saúde humana, bem como a contaminação de águas superficiais e subterrâneas (CARRARO, 1997). Outro 
problema relacionado ao uso desses produtos é a forma de descarte de suas embalagens, a vista que, quando descartados no meio ambiente causam um grande índice de contaminação.

Nos últimos anos, uma das práticas agrícolas que se tornou indispensável para a comercialização e que possui um grande volume de produção no Brasil é o plantio de hortaliças como o tomate (Lycopersicum esculentum Mill) e o pimentão (Capsicum annuum L), que são fundamentais para a alimentação. Porém, para o cultivo dessas culturas é necessário manter as áreas livres de plantas invasoras, já que estas se adaptam melhor ao ambiente do que as hortaliças. Com isso, o controle dessas lavouras exigem operações de grande significado socioeconômico para a diminuição das perdas e o retorno do investimento realizado pelo produtor. As áreas de plantio dessas culturas apresentam um grande índice de irregularidades, pois a ação das pragas e doenças sobre as mesmas tem levado o homem a investir na aplicação de defensivos agrícolas, que a princípio apresentam bons resultados, mas com o tempo causam danos irreparáveis ao ambiente e à saúde humana.

Diversas técnicas para o manejo do solo e sustentação da produção agrícola têm sido elaboradas ao longo dos anos com o intuito de minimizar os problemas ambientais acarretados pelo uso de produtos químicos, no entanto muitos agricultores desconhecem o real efeito que esses produtos causam quando aplicados de maneira inadequada. O presente trabalho teve como objetivo avaliar a água e solo de uma área de culturas mistas (tomate e pimentão) na zona rural do Município de São José do Belmonte-PE, bem como apresentar os resultados obtidos na avaliação da qualidade desses recursos comparando-os, sempre que possível, com os valores de referência estabelecidos pelos órgãos responsáveis pela manutenção dos mesmos, com o intuito de contribuir de maneira significativa para o desenvolvimento do processo agrícola realizado no local.

\section{Fundamentação Teórica}

O tomate é a hortaliça de maior comercialização no país, sendo muito apreciado pelo seu elevado valor nutritivo, rico em vitaminas A e C, fosfato e potássio. Desenvolve-se melhor em solos férteis, profundos e bem drenados, onde não tenham sido cultivadas solanáceas (PENTEADO, 2007). O tomateiro é uma planta que exige clima e temperatura específica para produzir bons frutos, se desenvolvendo melhor em climas moderadamente quentes com temperatura média de $20{ }^{\circ} \mathrm{C}$. É uma planta que requer boa disponibilidade de nutrientes e baixos teores de umidade. A qualidade da água usada para irrigação deve ser 
monitorada para que não leve a condições que causem doenças a planta. Não devem ser utilizadas águas suspeitas de contaminação, incluindo as de mananciais que recebem esgotos domésticos, industriais ou de outras áreas poluídas (PENTEADO, 2007). O preparo do solo deve ser feito acompanhando as curvas de níveis do terreno, com implementos tracionados por junta de boi ou por tração mecânica, dependendo da declividade do terreno, o qual é primordial realizar a análise do solo para identificar o estado nutricional (BRASIL, 2005). A correção do solo consiste na incorporação, de cálcio, fósforo, magnésio, enxofre e outros, em vista da deficiência desses nutrientes determinada na análise de solo. Em condições de campo, o plantio para as regiões brasileiras do Sudeste/Nordeste/Centro-oeste ocorre praticamente o ano todo. No Sul, os melhores plantios ocorrem em setembro a fevereiro, e, no Norte, de março a julho (PENTEADO, 2007).

O pimentão (Capsicum annuum L.) pertence a família das solanáceas e é uma das principais hortaliças produzidas no Brasil, além de possuir grande importância econômica, é rico em vitaminas A e C que são essenciais a nutrição humana (PENTEADO, 2007). O pimentão destaca-se entre as solanáceas pelo seu consumo e importância econômica no Brasil. No exterior, se destaca principalmente nos Estados Unidos, México, Itália, Japão e Índia. Os frutos de coloração verde e vermelha são mais aceitos, embora aqueles de cor laranja, amarelo e lilás, mais exóticos, têm alcançado bons preços pela excentricidade. A pigmentação influencia o sabor e o aroma, sendo que os frutos vermelhos são mais saborosos, porque apresentam $50 \%$ mais capsaína, uma substância picante. (SEDIYAMA et al., 2014). É uma planta de clima temperado quente, desenvolvendo bem em nossas condições, podendo ser plantadas de agosto até o outono. É muito sensível a baixas temperaturas e geadas, sendo recomendado seu plantio no inverno em estufas protegidas. Prefere solos bem drenados, férteis, ensolarados e ricos em matéria orgânica (PENTEADO, 2007).

No Brasil, há uma intensificação da produção de alimentos que são consumidos crus como frutas e hortaliças, o que tem gerado aumento nos índices de doenças causadas por contaminação externa, como provenientes do uso de defensivos agrícolas, água para irrigação não tratada e a falta de higiene no processamento e comercialização (COSTA et al., 2012). Dessa forma, a qualidade de água para fins de irrigação e a qualidade de solo são de fundamental importância para a diminuição do índice de problemas que prejudicam a saúde humana.

A água possui constituintes como o cálcio, magnésio iodo e ferro que são nutrientes 
fundamentais para a manutenção da vida, porém, por outro lado, alguns elementos como o manganês, sulfato, nitrato e sódio, podem alterar a qualidade da água, o que pode prejudicar a saúde humana (PARRON et al., 2011). No Brasil, existem órgãos responsáveis pela classificação de água e estabelece parâmetros químicos, físicos e biológicos de qualidade. A resolução $\mathrm{n}^{\circ} 357$ do Conselho Nacional do Meio Ambiente- CONAMA, de 17 de Março de 2005, estabelece a classificação das águas doces, salobras e salinas do território nacional, que se enquadram em 13 classes de qualidade. As águas destinadas para fins de irrigação de hortaliças que são consumidas cruas e de frutas que se desenvolvam rentes ao solo e que sejam ingeridas cruas sem remoção de película são classificadas na classe 1, que também engloba as águas destinadas ao abastecimento para consumo humano, após tratamento simplificado (CONAMA, 2005).

Para avaliação da qualidade do solo, de forma que possam ser sugeridas modificações nos sistemas de manejo em utilização pelos agricultores a tempo de evitar a sua degradação, é necessário definir atributos do solo e do ambiente sensíveis ao manejo e de fácil determinação (CARNEIRO, 2009). São vários os parâmetros utilizados para determinar a qualidade do solo, incluindo os parâmetros físicos que determinam a textura do solo e, os parâmetros químicos relacionados com condições que alteram as relações solo-planta, a qualidade da água, à capacidade tampão, a disponibilidade de nutrientes entre outras condições físicas (RIBEIRO et al., 2009).

\section{Metodologia}

O solo escolhido para a caracterização química é uma área rural de culturas mistas de hortaliças como o tomate (Lycopersicon esculentum Mill.) e o pimentão (Capsicum annuum L.) em Município de São José do Belmonte-PE. O local da coleta (FIGURA 1) de água consiste de uma barragem que recebe por meio de encanações, água de um poço artesiano próximo as culturas de hortaliças. As culturas são irrigadas a partir de sistema de gotejamento com água proveniente de uma barragem abastecida por um poço artesiano.

A área das coletas do solo (FIGURA 2) consiste do local onde se encontra a plantação de pimentão e tomate, além do local onde haviam sido realizadas queimas de embalagens vazias de defensivos agrícolas, as quais foram realizadas numa de profundidade de 0 à $30 \mathrm{~cm}$ em um ponto de cada cultura. 
Figura 1: Barragem cuja água é utilizada na irrigação de hortaliças.

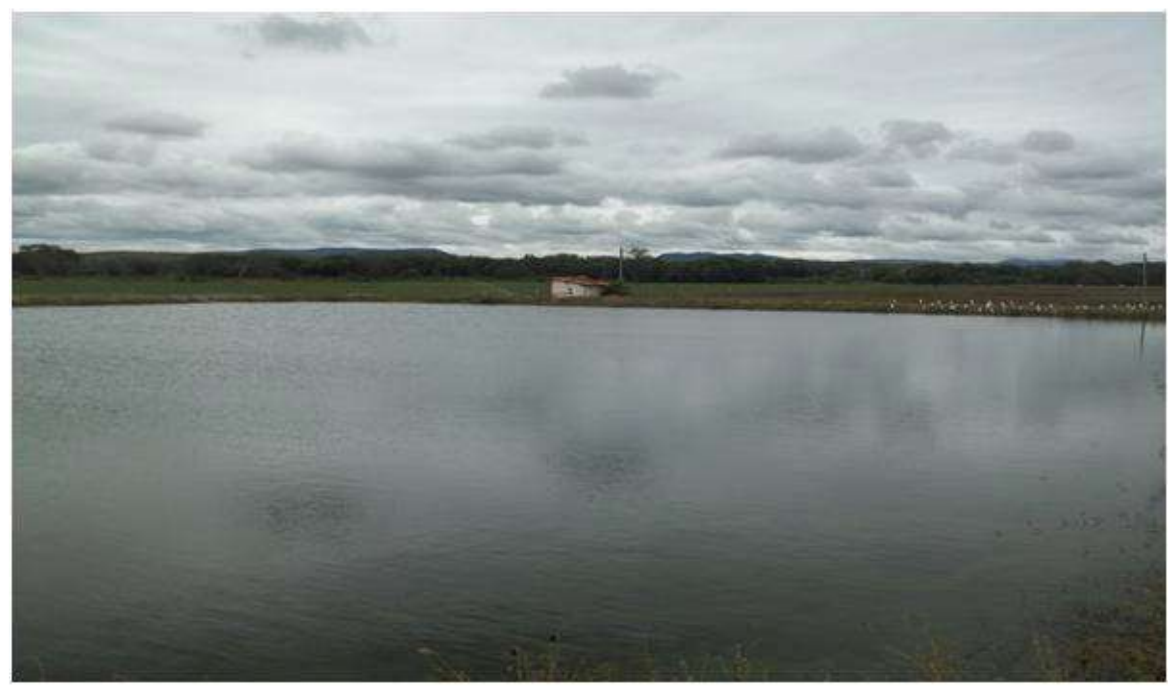

Fonte: Própria (2017).

Figura 2: Plantio das hortaliças.

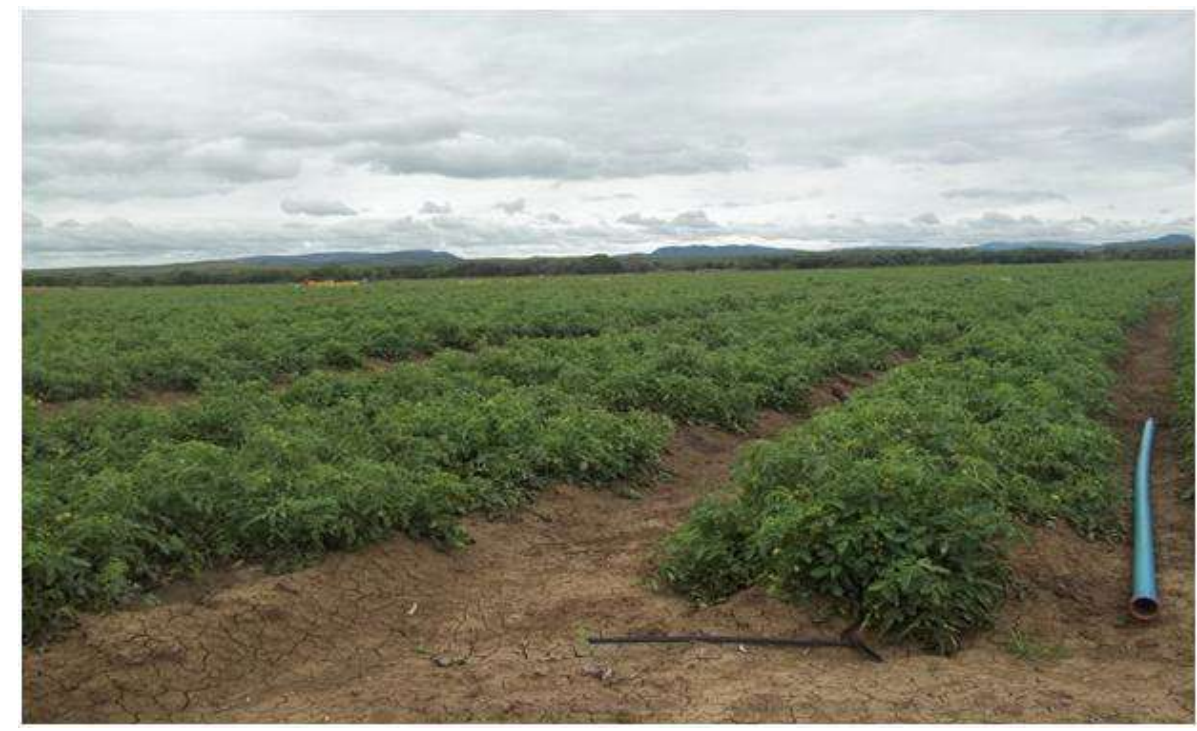

Fonte: Própria (2017).

As análises deste trabalho foram divididas em dois momentos: as análises de água e as análises de solo. Todas as análises foram realizadas em triplicatas.

A coleta e análise da água foram realizadas em recipiente de polietileno e as amostras foram levadas para o Laboratório de Química da Unidade Acadêmica de Serra Talhada (APHA, 2017). Para a água de irrigação foram realizados os ensaios de: temperatura $\left({ }^{\circ} \mathrm{C}\right)$ e 
condutividade elétrica $(\mathrm{CE})\left(\mu \mathrm{S} . \mathrm{cm}^{-1}\right)$ em condutivímetro RS 232, modelo CA 150; pH em pHmetro - LUTRON pH-206; acidez e alcalinidade, oxigênio dissolvido (OD); cloretos; dureza total (DT), dureza de cálcio; dureza de magnésio; determinação de nitrato por titulometria (APHA, 2017).

A coleta do solo foi realizada com amostra simples e em tempo final de colheita a uma profundidade de $30 \mathrm{~cm}$ em 3 pontos distintos. A amostra 1 foi coletada no solo do cultivo do tomate (FIGURA 3), a amostra 2 no cultivo do pimentão (FIGURA 4) e a amostra 3 no local onde realizaram queimadas das embalagens vazias de defensivos agrícolas (FIGURA 5). As amostras foram armazenadas em potes de polietileno e temperatura de aproximadamente $25^{\circ} \mathrm{C}$ até a realização das análises na Estação Experimental de Cana-de-Açúcar de Carpina UFRPE (EECAC/UFRPE). As análises de solo foram realizadas na EECAC-UFRPE, de acordo com as recomendações da EMBRAPA (1997).

Figura 3: Ponto de coleta do cultivo do tomate.

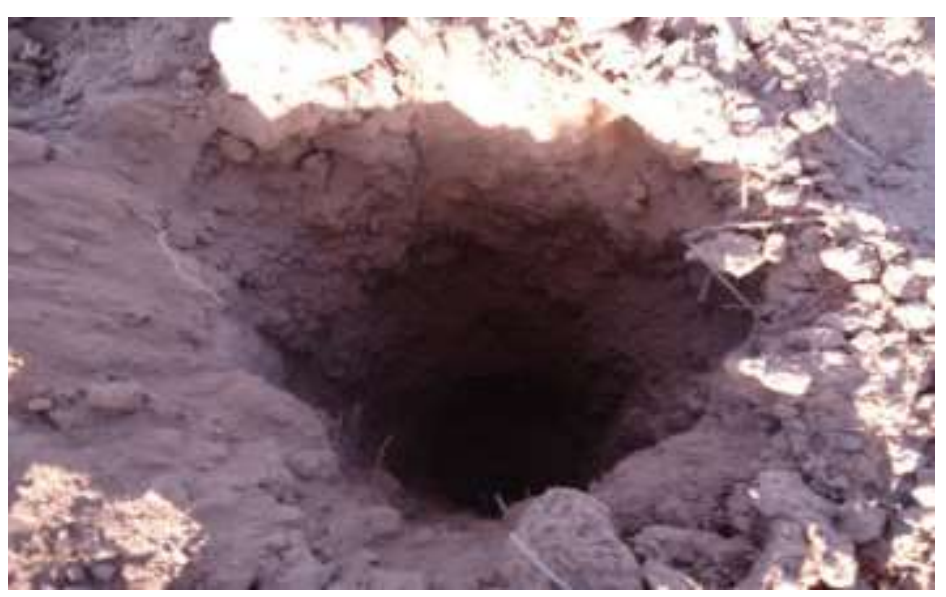

Fonte: Própria (2017).

Figura 4: Ponto de coleta do cultivo do pimentão. 


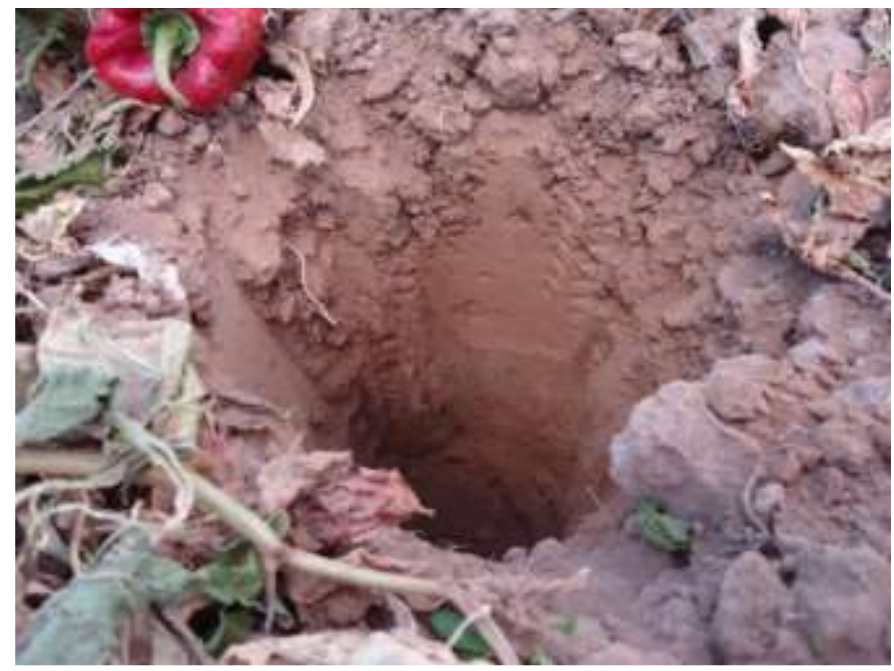

Fonte: Própria (2017).

Figura 5: Ponto de coleta do local das queimas de embalagens vazias.

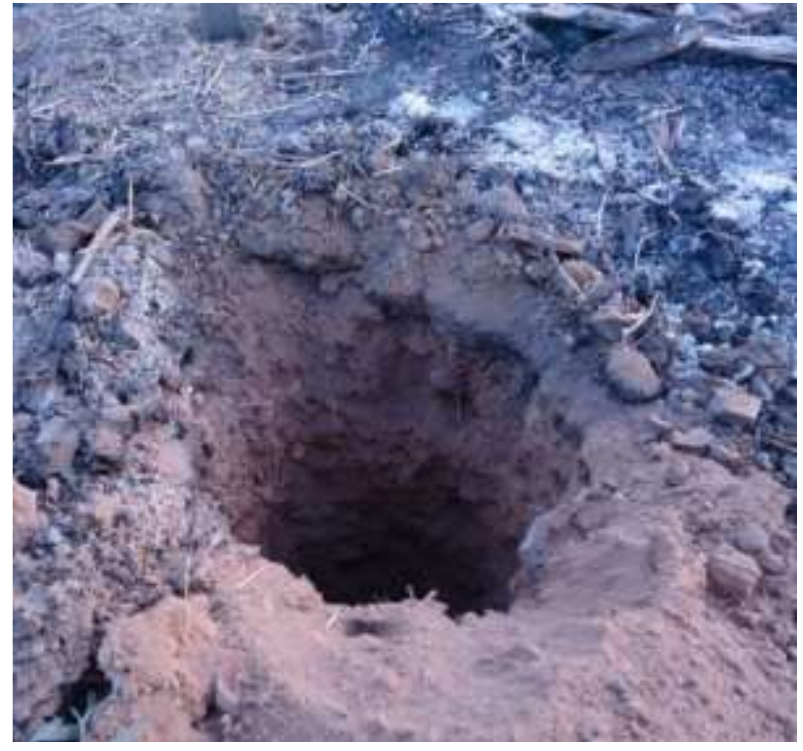

Fonte: Própria (2017).

\section{Resultados e Discussões}

Os resultados dos parâmetros analisados para amostra de água estão dispostos na Tabela 1.

Tabela 1: Resultados dos parâmetros analisados para amostra de água.

\begin{tabular}{lc}
\hline \multicolumn{1}{c}{ Parâmetros analisados } & Valores encontrados \\
\hline Alcalinidade e acidez $\left(\mathrm{mgCaCO}_{3} / \mathrm{l}\right)$ & acidez (ausente) alcalinidade 92 \\
Oxigênio dissolvido $(\mathrm{OD})(\mathrm{mg} / \mathrm{l})^{-1}$ & Ausente \\
Cloretos $\left(\mathrm{mg} \mathrm{Cl}^{-} / \mathrm{l}\right)$ & 53,98 \\
Dureza total $\left(\mathrm{mgCaCO}_{3} / \mathrm{l}\right)$ & 100,6 \\
Dureza de cálcio $\left(\mathrm{mgCaCO}_{3} / \mathrm{l}\right)$ & 30
\end{tabular}


Dureza de magnésio $\left(\mathrm{mgCaCO}_{3} / \mathrm{l}\right)$

Nitrato $(\mathrm{mg} / \mathrm{l})^{-1}$

Gás carbônico $\left(\mathrm{CO}_{2}\right)$

Temperatura $\left({ }^{\circ} \mathrm{C}\right)$

$\mathrm{pH}$

Condutividade $\left(\mu \mathrm{S} . \mathrm{cm}^{-1}\right)$

Fonte: Própria (2019).
70,6

Ausente

Ausente

26,3

7,84

253,7

A temperatura da água analisada apresentou valor entre $25^{\circ} \mathrm{C}$ e $30{ }^{\circ} \mathrm{C}$, sendo considerada uma temperatura comum para um clima semiárido e em período de seca. A condutividade elétrica apresentou considerável presença de íons dissolvidos na água. $\mathrm{O} \mathrm{pH}$ apresentado estava na uma faixa aceitável de qualidade apresentando natureza alcalina com pH de 7,84. Os resultados de acidez e alcalinidade não assumiram altos valores, estando presentes apenas na forma de bicarbonatos. Encontramos a ausência de OD, o que pode indicar contaminação da água com altas concentrações de fósforo e nitrogênio o que pode ter ocorrido devido a eutrofização do corpo hídrico (VIDAL \& NETO, 2014). A concentração de cloretos foi de 53,98 mg/L, valor dentro do permitido pelo Ministério da saúde que estabelece o valor de até $250 \mathrm{mg} / \mathrm{L}$ para que a água possa ser destinada ao consumo humano e para fins de irrigação.

Em relação à dureza total, foi encontrado valores que se enquadram na classificação de água com dureza moderada de acordo com o CONAMA. Vale ressaltar que além desses íons, outras substâncias que conferem dureza podem estar presentes nos corpos hídricos, como por exemplo, ferro, manganês, alumínio e zinco. Não houve a presença de nitratos indicando provável retenção do macronutriente no corpo hídrico (sedimentação ou desnitrificação) (VIDAL \& NETO, 2014).

Os resultados obtidos para os parâmetros químicos de solo (TABELA 2) foram interpretados de acordo com Coelho et al. (2009) e Raij et al. (2001) que classificam os teores dos constituintes presentes no solo em baixo, muito baixo, médio e alto.

Tabela 2: Valores obtidos nos parâmetros químicos de solo.

\begin{tabular}{lccc}
\hline Amostras analisadas & Amostra 1 & Amostra 2 & Amostra 3 \\
\hline $\mathrm{pH}$ & 6,0 & 6,0 & 7,7 \\
$\mathrm{P}\left(\mathrm{mg} / \mathrm{dm}^{3}\right)$ & 8,0 & 6,0 & 4,0 \\
$\mathrm{~K}\left(\mathrm{cmol}_{\mathrm{c}} / \mathrm{dm}^{3}\right)$ & 0,09 & 0,11 & 1,17 \\
$\mathrm{Na}\left(\mathrm{cmol}_{\mathrm{c}} / \mathrm{dm}^{3}\right)$ & 0,33 & 0,18 & 0,34 \\
$\mathrm{Al}\left(\mathrm{cmol}_{\mathrm{c}} / \mathrm{dm}^{3}\right)$ & 0,00 & 0,00 & 0,00
\end{tabular}




\begin{tabular}{|c|c|c|c|}
\hline $\mathrm{Ca}\left(\mathrm{cmol}_{\mathrm{c}} / \mathrm{dm}^{3}\right)$ & 4,0 & 6,60 & 14,00 \\
\hline $\operatorname{Mg}\left(\mathrm{cmol}_{\mathrm{d}} / \mathrm{dm}^{3}\right)$ & 2,70 & 6,50 & 4,80 \\
\hline $\mathrm{H}\left(\mathrm{cmol}_{\mathrm{c}} / \mathrm{dm}^{3}\right)$ & 1,30 & 2,20 & 0,00 \\
\hline $\mathrm{Fe}\left(\mathrm{mg} / \mathrm{dm}^{3}\right)$ & 132,70 & 133,50 & 114,20 \\
\hline $\mathrm{Cu}\left(\mathrm{mg} / \mathrm{dm}^{3}\right)$ & 1,90 & 2,90 & 2,50 \\
\hline $\mathrm{Zn}\left(\mathrm{mg} / \mathrm{dm}^{3}\right)$ & 4,40 & 5,10 & 13,10 \\
\hline $\operatorname{Mn}\left(\mathrm{mg} / \mathrm{dm}^{3}\right)$ & 40,70 & 31,80 & 65,80 \\
\hline $\mathrm{SB}^{*}$ (Soma de Bases) $\left(\mathrm{cmol}_{\mathrm{c}} / \mathrm{dm}^{3}\right)$ & 7,12 & 13,39 & 20,31 \\
\hline $\mathrm{CTC}^{*}\left(\mathrm{cmol}_{\mathcal{C}} / \mathrm{dm}^{3}\right)$ a pH 7 & 8,42 & 15,59 & 20,31 \\
\hline $\mathrm{V}^{*}(\%)$ & 84,56 & 85,89 & 100,0 \\
\hline MO* (\%) & 0,32 & 0,41 & 0,82 \\
\hline $\mathrm{M}^{*}(\%)$ & 0,00 & 0,00 & 0,00 \\
\hline
\end{tabular}

Fonte: Própria (2019).

Os valores do $\mathrm{pH}$ para as amostras 1 e 2 foram fracamente ácidos, apresentando uma faixa de valor que permite a absorção de nutrientes na planta, enquanto que a amostra 3 apresentou caráter alcalino sendo portanto um solo que necessitaria de correção se fosse utilizado para o cultivo.

Com base nos resultados obtidos, percebemos que a concentração do potássio estava relativamente abaixo em todas as amostras. Isso pode ser explicado pela assimilação do potássio do solo pelas plantas (época de colheita) ou ter ocorrido lixiviação no solo. Entretanto, as concentrações de cálcio e magnésio apresentaram valores médios para o local de cultivo do tomate (amostra 1), valores altos para o local de cultivo do pimentão (amostra 2) e o local das queimas de embalagens de defensivos agrícolas (amostra 3). As amostras de solo 1 e 3 apresentaram valores baixos de fósforo enquanto a amostra 2 apresentou valor médio (TABELA 2). Fósforo (P), Cálcio (Ca), Magnésio (Mg) e Potássio (K) são fontes de nutrientes essenciais para a manutenção das plantas. Uma boa proporção aproximada seria Ca:Mg:K 12:4:1 (COELHO et al., 2009).

Nos perfis analisados não houve a presença de alumínio e o índice de sódio foi baixo. Esses resultados contribuem para a qualidade do solo, porque alumínio e sódio em baixas concentrações promove melhor absorção de nutrientes essenciais para o desenvolvimento da planta.

Nas áreas estudadas a presença de $\mathrm{H}$ apresentou valores relativamente baixos para as amostras 1 e 2, uma vez que resultaram em um pH=6 (TABELA 2), mostrando ausente na amostra 3 . 
Os valores de SB nos solos são considerados altos, o que indica uma quantidade considerável de nutrientes nos solos estudados, apresentando valores de sódio baixos. Os valores encontrados de CTC são considerados altos para as amostras 2 e 3 e médio para a amostra 1. Em todas as amostras os valores encontrados de saturação por bases (V) são considerados altos (TABELA 2). O valor SB é composto de cálcio, magnésio, sódio e potássio, que são elementos chamados "bases". Serve para indicar se o solo tem nutrientes disponíveis para a planta (COELHO et al., 2009).

Como não houve a presença de alumínio nas amostras analisadas essa saturação também foi ausente, contribuindo de forma positiva para a qualidade do solo. A saturação por alumínio (m) é danoso para a planta levando a redução na produção (COELHO et al., 2009).

Os resultados obtidos para matéria orgânica são considerados baixos, (TABELA 2), o que pode contribuir de maneira negativa na qualidade do solo, porque esse atributo ajuda na absorção de nutrientes pelas plantas. Também haverá maior capacidade de retenção de nutrientes, melhor porosidade e maior capacidade de suportar solos salinos (COELHO et al., 2009).

Os resultados apresentaram valores altos para as três amostras (TABELA 2) (RAIJ et al., 2001). Os micronutrientes $\mathrm{Cu}, \mathrm{Fe}, \mathrm{Mn}$ e $\mathrm{Zn}$ são essenciais para o desenvolvimento da planta, embora sejam exigidos em menores quantidades do que os macronutrientes.

Com base nos resultados obtidos na análise granulométrica, o solo analisado apresentou uma textura média, porque possui teores aproximados de areia e argila (TABELA 3). A textura do solo interfere em algumas de suas propriedades, tais como: na porosidade, nas trocas gasosas, na interação da água, sua fixação no solo e disponibilidade, assim como nos nutrientes, na capacidade de troca de cátions (CTC), na permeabilidade do solo, entre outras propriedades (ALVES, 2013).

Tabela 3- Composição granulométrica das amostras de solo.

\begin{tabular}{lccc}
\hline & areia total \% & silte \% & argila \% \\
\hline Amostra 1 & 55,6 & 26,4 & 18,0 \\
Amostra 2 & 30,9 & 33,0 & 36,0 \\
Amostra 3 & 48,9 & 19,0 & 32,0 \\
\hline
\end{tabular}

Fonte: Própria (2019).

\section{Conclusões}


Os resultados obtidos nas análises de água e solo demonstram que os parâmetros oxigênio dissolvido e os teores de alguns macronutientes e micronutrientes se encontram em condições desfavoráveis para o desenvolvimento da planta, no entanto, estes podem ser corrigidos com cautela.

Porém, apesar dos resultados terem sidos satisfatórios sugere-se um acompanhamento periódico da área com avaliações frequentes e formas adequadas de manejo de produção, bem como do uso de produtos químicos e o descarte das embalagens vazias, tendo em vista que as hortaliças cultivadas são comercializadas para diversas regiões do estado.

\section{Referências}

AMERICAN PUBLIC HEALTH ASSOCIATION (APHA), American Water Works Association, Water Environment Federation. Standard Methods for the Examination of Water and Wastewater, 23RD Edition, 2017.

BRASIL. Ministério da agricultura pecuária e abastecimento. Recomendações Técnicas para a Produção do Tomate Ecologicamente Cultivado - TOMATEC. Rio de Janeiro - RJ, dez. 2005.

CARNEIRO, CM.A.C., SOUZA, E.D., REIS, E.F., PEREIRA, H.S., AZEVEDO, W.R. Atributos Físicos, Químicos e Biológicos de Solo de Cerrado sob Diferentes Sistemas de uso e Manejo. Revista Brasileira de Ciência do Solo, 33:147-157, 2009.

CARRARO, G. Agrotóxico e meio ambiente: Uma proposta de Ensino de Ciências e de Química. Universidade Federal do Rio Grande do Sul - Instituto de Química. Porto Alegre, Rio Grande do Sul, 1997.

COELHO, N. S.; GUIMARÃES, F. M.; SILVA, F. S.; RIBEIRO, A. S.; ROCHA, P.; MAGLHÃES, G. R.; OLIVEIRA, E. A. Adapta Sertão: tecnologias sociais de adaptação à mudanças climáticas. Nutrientes e solo. Rio de Janeiro, 2009.

CONSELHO NACIONAL DO MEIO AMBIENTE [CONAMA]. Resolução n³57 de 17 de Março de 2005. Disponível em: http://www.mma.gov.br/port/conama/res/res05/res35705.pdf.

COSTA, E. A., FIGUEREDO, E.A.T., CHAVES, C.S., ALMEIDA, P.C., VASCONCELOS, N.M., MAGALHÃES, I.M.C., MORAES, A.F., PAIXÃO, L.M.N., Avaliação Microbiológica de Alfaces (Lacutasativa L.) Convencionais e Orgânicas e a Eficiência de dois Processos de Higienização. Alimentos e Nutrição Araraquara. v. 23, n. 3, p. 387-392, jul./set. 2012.

EMBRAPA. Manual de métodos de análises de solo. Centro Nacional de Levantamento e Conservação do Solo. Rio de Janeiro: Embrapa Solos. 1997. 212p. 
PARRON, L. M.; MUNIZ, D. H. F.; PEREIRA, C. M. Manual de procedimentos de amostragem e análise físico-química de água. Colombo - PR:EMBRAPA Florestas 2011.

PENTEADO, R. S. Cultivo Ecológico de Hortaliças. 1. ed. Campinas. SP: Agricultura orgânica, 2007.

RAIJ, B.van; ANDRADE, J.C.; CANTARELLA, H. \&QUAGGIO, J.A. Análise química para avaliação da fertilidade de solos tropicais. Campinas, Instituto Agronômico, 2001. $285 \mathrm{p}$.

RIBEIRO, M. R.; SAMPAIO, E, V. de S.; GALINDO, I. C. L. Os solos e o processo de desertificação no semi-árido brasileiro. In: RIBEIRO, M. R. et al. Tópicos em ciência do solo. Viçosa, MG, Sociedade Brasileira de Ciência do Solo, 2009. p. 413- 59.

SEDIYAMA, M.A.N., SANTOS, M.R., VIDIGAL, S.M., PINTO, C.L.O., JACOB, L.L. Nutrição e produtividade de plantas de pimentão colorido, adubadas com biofertilizante de suíno. Revista Brasileira de Engenharia Agrícola Ambiental, v.18, n.6, p.588-594, 2014.

VIDAL, T.F., NETO CAPELO, J. Dinâmica de nitrogênio e fósforo em reservatório na região semiárida utilizando balanço de massa. Revista Brasileira de Engenharia Agrícola Ambiental, v.18, n.4, p.402-407, 2014. 